\title{
The feared postdilation complication in caustic esophageal stenosis: combined endoscopic and surgical treatment
}

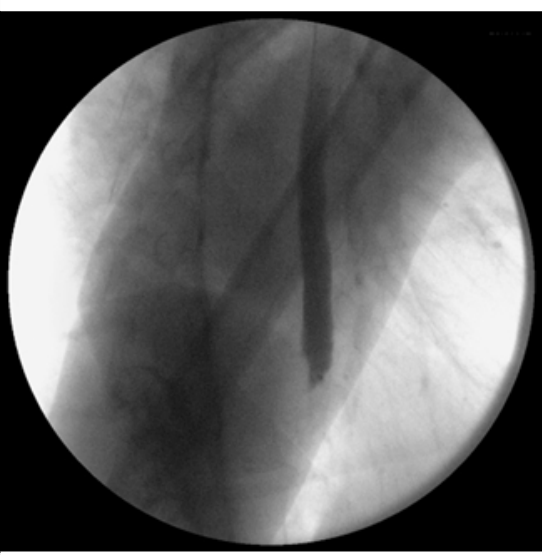

- Fig. 1 Fluoroscopic image showing the esophageal stricture and the absence of progression of contrast to the stomach.

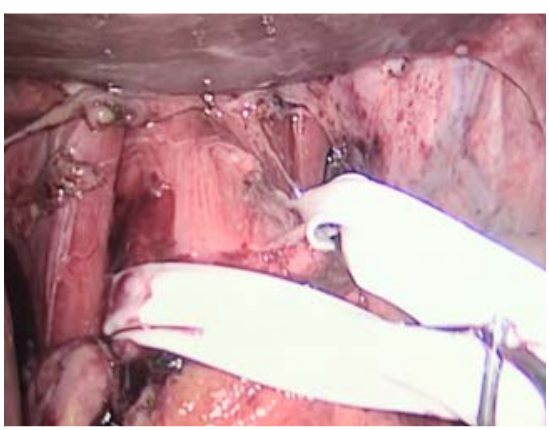

Fig. 3 Laparoscopic image of the esophageal perforation.

Esophageal stricture is a major complication after caustic ingestion. When the ingestion is associated with a suicide attempt, the damage is typically worse because a large amount is ingested [1]. Endoscopic dilation is the go-to for initial treatment, with surgical treatment being reserved for refractory cases. The success rate of dilation ranges from $40 \%$ to $90 \%$ $[2,3]$. Perforation is a complication with high morbidity and mortality that can occur during the dilation procedure, ranging from 0 to $32 \%$ of cases $[4,5]$. We describe a case of esophageal perforation during dilation and how it was treated with a combined endoscopic and surgical procedure.

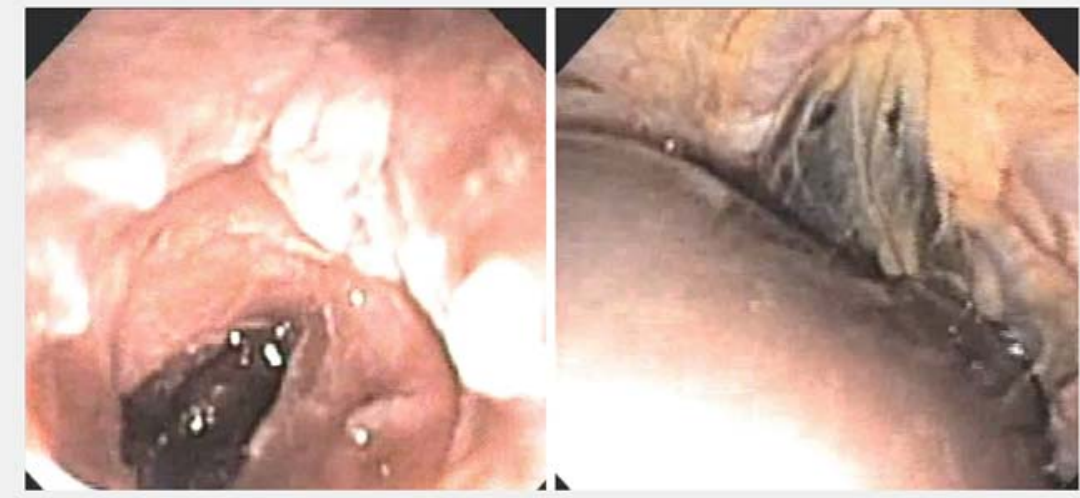

- Fig. 2 Endoscopic image showing the esophageal perforation into the abdominal cavity.
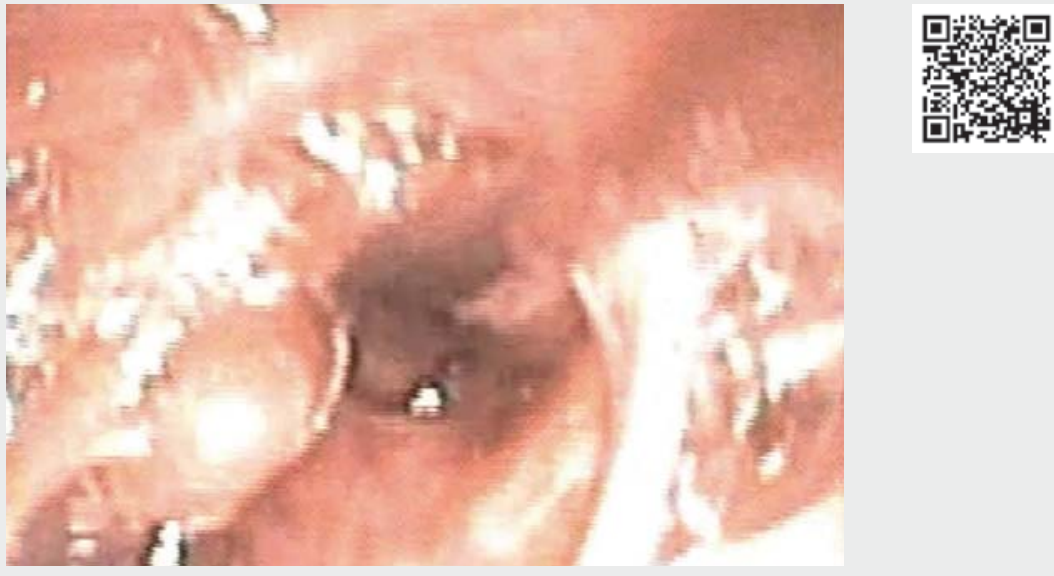

Video 1 A case of esophageal perforation during dilation and its treatment in the usual way with a combined endoscopic and laparoscopic procedure.

A 27-year-old man was referred to our department 40 days after ingesting caustic alkali in a suicide attempt. The stricture was identified $25 \mathrm{~cm}$ from the incisors ( Fig.1). A contrast study showed segmental stricture up to the esophagogastric junction. A flexible guidewire was passed under fluoroscopy and dilation was performed with Savary-Miller bougies up to 8 French ( $\mathrm{Fr}$ ). At the end of the dilation, when the review was performed, an extensive perforation was seen in the distal esophagus with exposure of the ab-

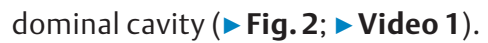

The operation was performed with combined laparoscopic and endoscopic procedures. The perforation was identified ( Fig.3) and a gastrotomy was performed on the distal body. The gastroscope $(5.4 \mathrm{~mm})$ passed through an abdominal trocar and a retrograde guidewire was passed through the esophagogastric junction and externalized through the mouth. With the guidewire and under 


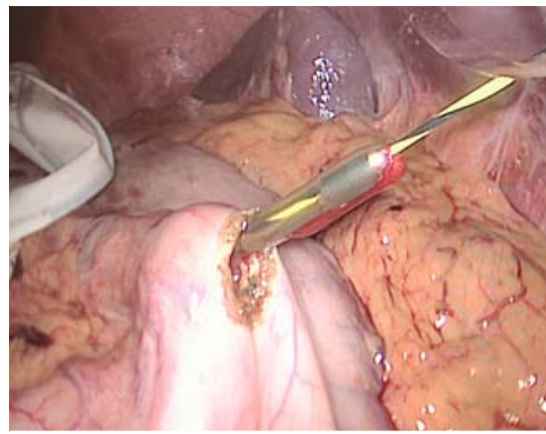

- Fig. 4 Intraoperative esophageal dilation with bougies up to $10 \mathrm{Fr}$.

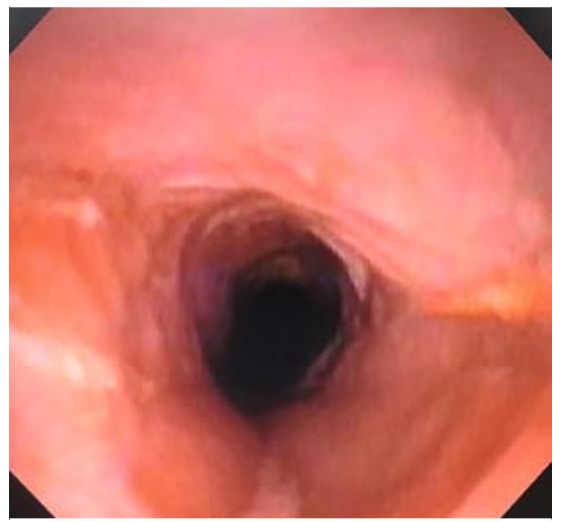

- Fig. 5 Follow-up endoscopy was performed after 1 month, showing complete healing of the perforation. laparoscopic vision, dilation was performed using Savary-Miller bougies up to $10 \mathrm{Fr}$ ( $\mathbf{F i g . 4 )}$. Another guidewire was passed to the duodenum and a nasoenteral tube was positioned. The esophagus was sutured and covered with an omental patch. Finally, the cavity was drained and the gastrostomy was performed through the gastrotomy orifice.

The patient progressed well, accepting food through the nasoenteral tube, and was discharged after psychiatric evaluation. Follow-up endoscopy was performed after 1 month, showing complete healing of the perforation ( $\mathbf{F i g . 5}$ ).

Endoscopy_UCTN_Code_CPL_1AH_2AF

\section{Competing interests}

The authors declare that they have no conflict of interest.

\section{The authors}

Vitor Massaro Takamatsu Sagae, Igor Braga

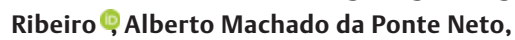
Sergio Eiji Matuguma, Spencer Cheng, Marcos Eduardo Lera dos Santos, Eduardo Guimarães Hourneaux de Moura $\odot$

Gastrointestinal Endoscopy Unit, Hospital das Clínicas da Faculdade de Medicina da

Universidade de São Paulo

\section{Corresponding author}

\section{Igor Braga Ribeiro, MD}

Av. Dr Enéas de Carvalho Aguiar, 225,

60 andar, bloco 3, Cerqueira Cesar,

05403-010 São Paulo, SP, Brazil

igorbraga1@gmail.com

\section{References}

[1] Arévalo-Silva C, Eliashar R, Wohlgelernter J et al. Ingestion of caustic substances: a 15-year experience. Laryngoscope 2006; 116: 1422-1426

[2] Tharavej C, Pungpapong S-U, Chanswangphuvana P. Outcome of dilatation and predictors of failed dilatation in patients with acid-induced corrosive esophageal strictures. Surg Endosc 2018; 32: 900-907
[3] Josino IR, Madruga-Neto AC, Ribeiro IB et al. Endoscopic dilation with bougies versus balloon dilation in esophageal benign strictures: systematic review and meta-analysis. Gastroenterol Res Pract 2018. doi:10.1155/ 2018/5874870

[4] Song HY, Han YM, Kim HN et al. Corrosive esophageal stricture: safety and effectiveness of balloon dilation. Radiology 1992; 184: 373-378

[5] Poley J-W, Steyerberg EW, Kuipers EJ et al. Ingestion of acid and alkaline agents: outcome and prognostic value of early upper endoscopy. Gastrointest Endosc 2004; 60: 372-377

Bibliography

Endoscopy 2021; 53: E446-E447

DOI 10.1055/a-1339-0588

ISSN 0013-726X

published online 27.1.2021

(c) 2021. Thieme. All rights reserved.

Georg Thieme Verlag KG, Rüdigerstraße 14,

70469 Stuttgart, Germany

\section{ENDOSCOPY E-VIDEOS}

https://eref.thieme.de/e-videos

回起 Endoscopy E-Videos is a free access online section, reporting 靣辌: on interesting cases and new techniques in gastroenterological endoscopy. All papers include a high quality video and all contributions are freely accessible online.

This section has its own submission website at https://mc.manuscriptcentral.com/e-videos 